\title{
Severe Hypoxemia in a Healthy Donor for Allogeneic Hematopoietic Stem Cell Transplantation after Only the First Administration of Granulocyte-Colony Stimulating Factor
}

\author{
Keita Yamamoto ${ }^{a}$ Noriko Doki ${ }^{a}$ Yasushi Senoo ${ }^{a}$ Yuho Najima ${ }^{a}$ Takeshi Kobayashi $^{a}$ \\ Kazuhiko Kakihana $^{a}$ Kyoko Haraguchi $^{b}$ Yoshiki Okuyamab Hisashi Sakamaki ${ }^{a}$ \\ Kazuteru Ohashia \\ a Hematology Division, Tokyo Metropolitan Cancer and Infectious Diseases Center, Komagome Hospital, Tokyo, Japan; \\ ${ }^{b}$ Division of Transfusion and Cell Therapy, Tokyo Metropolitan Cancer and Infectious Diseases Center, Komagome Hospital, Tokyo, Japan
}

\section{Keywords}

Severe hypoxemia - Healthy donor .

Allogeneic hematopoietic stem cell transplantation .

Allo-HSCT . Peripheral blood stem cells - PBSCs .

Granulocyte-colony stimulating factor - G-CSF

\section{Summary}

Background: Granulocyte-colony stimulating factor (GCSF) is widely used to mobilize peripheral blood stem cells (PBSCs) in healthy donors. A few reports have shown that some healthy donors developed acute respiratory distress syndrome or capillary leak syndrome after more than several rounds of G-CSF administration or leukapheresis. Case Report: We report the case of a healthy donor for allogeneic stem cell transplantation who developed severe hypoxemia $1 \mathrm{~h}$ after only the first administration of G-CSF. The donor was administered 10 $\mu \mathrm{g} / \mathrm{kg}$ G-CSF (lenograstim) subcutaneously for PBSC mobilization. $1 \mathrm{~h}$ after the first administration of G-CSF, the donor suddenly presented with dry cough and dyspnea. The oxygen saturation by pulse oximetry $\left(\mathrm{SpO}_{2}\right)$ in the room air was $88 \%$. An electrocardiogram and chest radiography revealed no abnormalities. We excluded other causes of severe hypoxemia and diagnosed the donor with hypoxemia due to G-CSF administration, which was subsequently terminated. The donor was administered 2 $\mathrm{I} / \mathrm{min}$ oxygen via a nasal cannula and $100 \mathrm{mg}$ hydrocortisone intravenously. He subsequently recovered, and
$\mathrm{SpO}_{2}$ in the room air returned to $98 \% 10 \mathrm{~h}$ after hypoxemia. Conclusion: These respiratory symptoms might be related to anaphylactoid or hypersensitivity reaction. The donors should be observed for at least $1 \mathrm{~h}$ after the first administration of G-CSF.

(c) 2016 S. Karger GmbH, Freiburg

\section{Introduction}

Granulocyte-colony stimulating factor (G-CSF) has been widely used to mobilize peripheral blood stem cells (PBSCs) in healthy donors $[1,2]$. Many reports have described well-recognized transient adverse effects, including bone pain, headache, fatigue, nausea, fever, insomnia, anorexia, and myalgias [1-3]. Regarding pulmonary events, interstitial pneumonitis, pulmonary edema, and lung fibrosis are very rare [2]. However, a few cases of acute respiratory distress syndrome (ARDS) [3-6] and capillary leak syndrome [7] after administration of G-CSF have been reported in healthy donors. These cases developed ARDS or capillary leak syndrome after more than several rounds of G-CSF administration or leukapheresis [3-7]. We here report the case of a healthy donor for allogeneic hematopoietic stem cell transplantation (allo-HSCT) who developed severe hypoxemia $1 \mathrm{~h}$ after only the first administration of G-CSF.

\section{KARGER}

() 2016 S. Karger GmbH, Freiburg 


\section{Case Report}

A 50-year-old man was admitted as a related donor for allo-HSCT. He did not have a medical or allergy history. Physical examination, chest radiography, and laboratory examinations were normal, and his body mass index (BMI) was $23.8 \mathrm{~kg} / \mathrm{m}^{2}$. Spirometry on admission demonstrated normal data with $126.2 \%$ vital capacity and 78 forced expiratory volume in $1 \mathrm{~s}$. The oxygen saturation by pulse oximetry $\left(\mathrm{SpO}_{2}\right)$ in the room air was $98 \%$. The donor was administered 10 $\mu \mathrm{g} / \mathrm{kg} \mathrm{G}$-CSF (lenograstim) subcutaneously for PBSC mobilization. $1 \mathrm{~h}$ after the first administration of G-CSF, the donor suddenly presented with dry cough and dyspnea, but developed neither fever nor rash. On physical examination, he did not show wheezes, crackles, pain, abdominal symptoms, lymphoadenopathy, or pharyngeal abnormalities. Although the $\mathrm{SpO}_{2}$ in the room air was $88 \%$, the donor was found to have stable observations: body temperature $36.5^{\circ} \mathrm{C}$, purse rate $66 \mathrm{~min} /$ regular, and blood pressure 99/66 mm Hg. An electrocardiogram revealed no abnormalities. Chest radiography demonstrated no infiltration, but slight cardiac dilatation was observed. 2 1/min oxygen administration via a nasal cannula was started. The laboratory findings demonstrated a white blood cell count of $10,100 / \mu \mathrm{l}$, aspartate aminotransferase of $22 \mathrm{U} / \mathrm{l}$, alanine transaminase of $31 \mathrm{U} / 1$, lactate dehydrogenase of $145 \mathrm{U} / 1$ (normal range 115$245 \mathrm{U} / \mathrm{l})$, alkaline phosphatase of $386 \mathrm{IU} / \mathrm{l}$, creatine kinase of $88 \mathrm{U} / 1$, C-reactive protein of $0.15 \mathrm{mg} / \mathrm{dl}$, sialylated carbohydrate antigen KL- 6 of $25 \mathrm{IU} / \mathrm{ml}$ (normal range 0-499 IU/ml), and pulmonary surfactant protein-D of $32.8 \mathrm{ng} / \mathrm{ml}$ (normal range 0-109.9 $\mathrm{ng} / \mathrm{ml}$ ). We excluded the possibility of acute infection. No new medications had been introduced other than G-CSF. These results suggest that severe hypoxemia may have developed after exposure to G-CSF, and thus, G-CSF administration was terminated. The donor was administered 100 mg hydrocortisone intravenously after hypoxemia. He subsequently recovered, and $\mathrm{SpO}_{2}$ in the room air returned to $98 \% 10 \mathrm{~h}$ after hypoxemia. Computed tomography of the chest on day 5 after administration of G-CSF showed no significant abnormalities. The donor was discharged from the hospital in good condition 5 days after hypoxemia. He fully recovered and showed a normal complete blood cell count, normal $\mathrm{SpO}_{2}$, and normal chest radiography 2 months after administration of G-CSF. The patient to whom the donor had planned to donate PBSCs underwent emergent cord blood transplantation, and engraftment was achieved.

\section{Discussion}

In this case, we were able to exclude other causes of hypoxemia aside from the administration of G-CSF.

In patients receiving chemotherapy, the reported pulmonary side effects of G-CSF include cough, dyspnea, and interstitial or alveolar infiltrates with mild to severe blood gas deterioration [3] Lung toxicity in allogeneic stem cell donors has been reported in only a few cases [3-6]. The present donor did not demonstrate bilateral infiltrates and interstitial pneumonitis at hypoxemia. The values of sialylated carbonhydrate antigen $\mathrm{KL}-6$, and pulmonary surfactant protein-D were normal. These findings do not meet the diagnostic criteria for acute lung injury [8], ARDS [8], and druginduced pneumonitis [9]. On the other hand, anaphylactic reactions including lung involvement due to G-CSF application are well known, and several cases are reported [10-13] as well as hypersensitivity reaction mimicking anaphylaxis [14]. Although these cases showed acute anaphylactic reactions within 15 min after the administration of G-CSF, an acute reaction was not observed in the current case. However, as the donor recovered from hypoxemia rapidly after a single dose of $100 \mathrm{mg}$ hydrocortisone, these respiratory symptoms might be related to an anaphylactoid or hypersensitivity reaction.

A previous report on healthy donors showed that gas exchange is significantly disturbed during G-CSF administration and is reversible on discontinuation of G-CSF [15]. Because levels of both partial pressure of $\mathrm{CO}_{2}$ in arterial blood and alveolar-arterial oxygen difference are significantly higher after G-CSF administration, G-CSF may induce an increase in the physiologic dead space and result in a decreased gas exchange capacity of alveoli [15]. Furthermore, G-CSF leads to induction of serum IL- 6 and polymorphonuclear leukocyte elastase, which are important mediators of acute lung injury [15]. On the other hand, apoptosis plays an important role in the regulation of several biological processes, including inflammatory response [16]. Several inflammatory mediators such as G-CSF and granulocyte-macrophage colony stimulator factor (GM-CSF) inhibit apoptosis and prolong neutrophil survival in vitro, which leads to neutrophilic alveolitis [16]. These mechanisms may be associated with hypoxemia after exposure to G-CSF.

Regarding other factors associated with hypoxemia under G-CSF use, human leukocyte antigen (HLA) phenotypes such as HLA-B51 or HLA-B52 have also been associated with the onset of G-CSF-related pulmonary toxicity in patients receiving chemotherapy or stem cell transplant [17]. Yoshida et al. [15] reported two donors with a BMI of more than $28 \mathrm{~kg} / \mathrm{m}^{2}$ who experienced respiratory symptoms with only a slight reduction of $\mathrm{PaO} 2$. In our present case, the donor did not show the HLA-B51 or HLA-B52 phenotype, and his BMI was less than $28 \mathrm{~kg} / \mathrm{m}^{2}$.

\section{Conclusion}

G-CSF is a widely used agent for inducing mobilization of PBSCs in donors. This case report describes acute hypoxemia after the first G-CSF application. Acute lung injury or acute respiratory distress syndrome were not confirmed by the findings, and hypoxemia due to an anaphylactoid reaction cannot be excluded. The donors should be observed for at least $1 \mathrm{~h}$ after giving the initial dose of G-CSF.

This case also emphasizes the need for clinical awareness when administering G-CSF for mobilization of PBSCs.

\section{Disclosure Statement}

The authors declare no conflict of interest. 


\section{References}

1 Pulsipher MA, Chitphakdithai P, Logan BR, Shaw BE, Wingard JR, Lazarus HM, Waller EK, Seftel M, Stroncek DF, Lopez AM, Maharaj D, Hematti P, O’Donnell PV, Loren AW, Leitman SF, Anderlini P, Goldstein SC, Levine JE, Navarro WH, Miller JP, Confer DL: Acute toxicities of unrelated bone marrow versus peripheral blood stem cell donation: results of a prospective trial from the National Marrow Donor Program. Blood 2013;121:197-206.

2 Hölig K: G-CSF in healthy allogeneic stem cell donors. Transfus Med Hemother 2013;40:225-235.

$\checkmark 3$ D’Souza A, Jaiyesimi I, Trainor L, Venuturumili P. Granulocyte colony-stimulating factor administration: adverse events. Transfus Med Rev 2008;22:280-290.

4 Azoulay E, Attalah H, Harf A, Schlemmer B, Delclaux C: Granulocyte colony-stimulating factor or neutrophil-induced pulmonary toxicity: myth or reality? Systematic review of clinical case reports and experimental data. Chest 2001;120:1695-1701.

5 Arimura K, Inoue H, Kukita T, Matsushita K, Akimo M, Kawamata N, Yamaguchi A, Kawada H, Ozak A, Arima N, Te C: Acute lung injury in a healthy donor during mobilization of peripheral blood stem cells using granulocyte-colony stimulating factor alone. Haematologica 2005;90:e27-e29
Wetzko K, Blechschmidt M, Hölig K, Poppe-Thiede K, Ganepola S, Fischbach R, Ordemann R, Laniado M, Schulte-Hubbert B, Schuler M, Cotta L, Braumann D, Ehninger G, Kroschinsky F: Pulmonary adverse events in unrelated donors of peripheral blood stem cells. Transfus Med 2013;23:69-71.

7 de Azevedo AM, Goldberg Tabak D: Life-threatening capillary leak syndrome after G-CSF mobilization and collection of peripheral blood progenitor cells for allogeneic transplantation. Bone Marrow Transplant 2001; 28:311-312.

8 Bernard GR, Artigas A, Brigham KL, Carlet J, Falke K, Hudson L, Lamy M, Legall JR, Morris A, Spragg R: The American-European Consensus Conference on ARDS. Definitions, mechanisms, relevant outcomes, and clinical trial coordination. Am J Respir Crit Care Med 1994;149:818-824.

9 Ohnishi H, Yokoyama A, Yasuhara Y, Watanabe A, Naka T, Hamada H, Abe M, Nishimura K, Higaki J, Ikezoe J, Kohno N: Circulating KL-6 levels in patients with drug induced pneumonitis. Thorax 2003;58:872875.

10 Jaiyesimi I, Giralt SS, Wood J: Subcutaneous granulocyte colony-stimulating factor and acute anaphylaxis. N Engl J Med 1991;325:587.

11 Batel-Copel L, Mommeja-Marin H, Oudard S, Chauvenet L, Pujade-Lauraine E, Coupier J, Bernadou A: Anaphylactic reaction after a first filgrastim (G-CSF) injection. Eur J Cancer1995;31A:13-14.
Keung YK, Suwanvecho S, Cobos E: Anaphylactoid reaction to G-CSF used in mobilization of peripheral blood stem cells. Bone Marrow Transplant1999;23: 200-201.

13 Tulpule S, Shaw BE, Makoni P, Little AM, Madrigal JA, Goldman JM: Severe allergic reaction with anaphylaxis to G-CSF (lenograstim) in a healthy donor. Bone Marrow Transplant 2009;44:129-130.

14 Tholpady A, Chiosea I, Lyons JJ, Baird K, Leitman SF: Systemic hypersensitivity reaction mimicking anaphylaxis after first filgrastim administration in a healthy donor. Transfusion 2013;53:1146-1147.

15 Yoshida I, Matsuo K, Teshima T, Hashimoto D, Tanimoto Y, Harada M, Tanimoto M: Transient respiratory disturbance by granulocyte-colony-stimulating factor administration in healthy donors of allogeneic peripheral blood progenitor cell transplantation. Transfusion 2006 ;46:186-192.

16 Barros de Souza A, Brandão dos Santos F, Negri EM, Zin WA, Rocco PRM: Lung tissue remodelling in the acute respiratory distress syndrome. J Pneumologia 2003;29:235-245.

17 Takatsuka H, Takemoto Y, Mori A, Okamoto T, Kanamaru A, Kakishita E: Common features in the onset of ARDS after administration of granulocyte colonystimulating factor. Chest 2002;121:1716-1720. 